\title{
O Corpo Glorioso: um diálogo entre Merleau-Ponty e Michel Serres
}

\author{
Ana Elisa Antunes Viviani'
}

\begin{abstract}
RESUMO: Este artigo procura explorar dois autores que, embora pareçam antagônicos em seu enraizamento teórico, as concepções de corpo desenvolvidas por eles tornam inevitável uma aproximação, impelindo a realização de um diálogo entre ambos. De um lado, Merleau-Ponty, herdeiro da fenomenologia husserliana, desenvolve inicialmente a noção de corpo préobjetivo para depois aperfeiçoá-lo até a noção de corpo sentiente. De outro lado, Michel Serres, por sua vez, tem uma trajetória heterodoxa na filosofia, mais voltada para o mundo em turbulência que para o mundo estático, o que faz com que conceba o corpo como quimera. Ambos pensadores interseccionam-se em conceitos como carne, sentidos e espessura do mundo.
\end{abstract}

Palavras-chave: corpo, sentidos, carne

ABSTRACT: This article presents an investigation between two philosophers whose theoretical background may be seen as contrastive. However. since both of them have developed an understanding in body it is inevitable to carry out a discussion on this topic. On the one hand, Merleau-Ponty, heir of the Husserl's phenomenology, firstly develops the notion of pre-objective body and then the concept of sentient-body. On the other hand, Michel Serres and his unorthodox career on philosophy focuses the world as turbulence instead of a static phenomen, wich brings him to the concept of the body as chimera. The intersecction of these two authors comes up on concepts such as flesh, sense and the deepness of the world.

Key-words: body, senses, meat

1 Mestre em Ciências da Comunicação pela Escola de Comunicações e Artes da Universidade de São Paulo 
RÉSUMÉ: Cet article veut explorer deux penseurs qui même opposé dans leurs racines théoriques, les conceptions du corps développées par eux rendent un inévitable approche, ce que pousse l'accomplissement d'un dialogue entre eux. D'un côté Merleau-Ponty, héritier de la phénoménologie de Husserl, développe au commencement la notion du corps préobjectif pour après le perfeccioner jusqu' au concept du corps-sentient. D'autre côté Michel Serres, alternativement, a une trajectoire hétérodoxe en philosophie que considère le monde en turbulence au lieu d'un monde statique. Ça le fait concevoir le corps comme chimère. $L$ 'intersection des deux penseurs se produit autour des concepts de la chair, des sens et de l'épaisseur du monde.

Mots-clé: corps, sens, chair

RESUMEN: Este artículo presenta una investigação entre dos pensadores, aunque opuestos en sus raíces teóricas, sus conceptos del cuerpo hacen inevitable un acercamiento, impulsando la realización de un diálogo entre ellos. Por un lado, Merleau-Ponty, herdero del fenomenología de Husserl, desarrola inicialmente la noción del cuerpo pré-objectivo y más adelante el concepto del cuerpo-sentiente. Por outro lado, Michel Serres tiene una trayectoria heterodoxa en la filosofía, enfocando el mundo en turbulencia en vez de un mundo estático. Esto lo hace concibir un cuerpo como quimera. El intersección de estos dos autores sucede en conceptos tales como carne, sentidos y espesura del mundo.

Palavras-clave: cuerpo, sentidos, carne.

\section{O corpo pré-objetivo}

Herdeiro da fenomenologia desenvolvida por Edmond Husserl, MerleauPonty é crítico da análise reflexiva cartesiana fundamentada na res extensa e na res intensa e adota a noção de intencionalidade (a consciência é sempre consciência de algo). Apesar de ainda haver alguns rastros idealistas na fenomenologia (e que desaparece na fase final da vida de Merleau-Ponty), especialmente devido à idéia de um cogito transcendental e pelo fato de ser uma filosofia eidética, Merleau-Ponty percebe esses vestígios e procura escapar deles, adotando a idéia de um corpoconsciência que, em sua relação perceptiva com o mundo, envolve-se por ele, instalase nele e, por fim, dissolve-se nele. Daí seu profundo interesse na questão da nossa percepção e do sentir. 
Segundo Merleau-Ponty, por séculos, tanto ciência, quanto filosofia, conduziam-se por uma percepção que procurava fixar o ser, pois somente assim seria possível elaborar conceitos e pressupostos. E, desta maneira, o corpo, tanto em sua concepção mecanicista, quanto em sua concepção psicológica, resumia-se de fato a um objeto entre outros. Visto como um conjunto de reações físico-químicas, o sentir referia-se apenas "à recepção de uma qualidade" (1999, p. 88) e que a fisiologia procurava desvendar mecanicamente em todo seu processo. Assim, "enquanto o corpo vivo se tornava um exterior sem interior, a subjetividade tornava-se um interior sem exterior, um espectador imparcial.” (1999, p. 88).

Merleau-Ponty procura compreender como se dá a formação de um pensamento objetivo e que possa explicar o psíquico também. Para isso, usa como exemplo dois casos: o de pacientes que ainda sentem seus membros amputados (membros fantasmas) e o de pacientes que não conseguem sentir determinado membro do corpo (anosognose). Em ambas situações, nem a explicação puramente física e nem a explicação puramente psíquica dão conta de compreendê-las, pois ficam restritas ao mundo objetivo. Apenas um pensamento que surja a partir dessas duas visões, ou seja, um pensamento orgânico, unindo o psíquico e o físico, encontra explicação para as duas situações:

Para descrever a crença no membro fantasma e a recusa da mutilação, os autores falam de uma 'repressão' ou de um 'recalque orgânico'. Esses termos pouco cartesianos obrigam-nos a formar a idéia de um pensamento orgânico pelo qual a relação entre o 'psíquico' e o 'físico' se tornaria concebível. [...] Assim, o que encontramos atrás do fenômeno da substituição é o movimento do ser no mundo [...]. (MERLEAU-PONTY, 1999, p. 117)

Com isso, o autor supera a clássica dicotomia corpo-alma afirmando que tanto na situação do membro fantasma quanto na da recusa da mutilação, a alma se espalha por todo o corpo. O pensamento orgânico é na verdade a idéia de MerleauPonty de uma visão pré-objetiva que seria uma zona de possibilidades de ação no mundo; uma zona em que os movimentos se anunciam, mas não objetivamente; uma zona entre a presença e a ausência. Essa visão pré-objetiva é o que ele denomina "ser no mundo" e que conjuga o psíquico e o fisiológico. Essa região é também denominada por ele como mundo inter-humano, isto é, uma região em que o Eu se estende no mundo. Daí o papel fundamental do corpo: "O corpo é o veículo do ser no 
mundo, e ter um corpo é, para um ser vivo, juntar-se a um meio definido, confundirse com certos projetos e empenhar-se continuamente neles.” (1999, p. 122)

Os pacientes que sofrem tanto do membro fantasma quanto da anosognose comprovam a ambigüidade existente entre o corpo habitual e o corpo atual. No corpo habitual, delineiam-se os gestos dos membros que desaparecem no atual. Mas

como posso perceber objetos enquanto manejáveis, embora não possa mais manejá-los? É preciso que o manejável tenha deixado de ser aquilo que manejo atualmente para tornar-se aquilo que se pode manejar, tenha deixado de ser um manejável para mim e tenha-se tornado como que um manejável em si. Correlativamente, é preciso que meu corpo seja apreendido não apenas em uma experiência instantânea, singular, plena, mas ainda sob um aspecto de generalidade e como um ser impessoal. (MERLEAU-PONTY, 1999,p. 123)

O membro fantasma é sentido porque ele é quase-presente; não se trata de uma simples rememoração porque o paciente o sente. Nesta situação, assim como no recalque, congelamos o tempo pessoal, enquanto o impessoal continua a acontecer. Essa fixação também não se confunde com a recordação, pois "este passado que permanece nosso verdadeiro presente não se distancia de nós e esconde-se sempre atrás de nosso olhar em lugar de dispor-se diante dele.” (1999, p. 124) Segundo Merleau-Ponty, conjugamos ao lado de nossa existência pessoal, uma margem quase impessoal, ou pré-pessoal. O organismo é essa forma que recalcamos para que a existência pessoal possa emergir e que exerce "o papel de um complexo inato" (1999, p. 125), mas que também exerce o "movimento da existência." (1999, p. 125) Quando somos atingidos por algum fato que nos toca, o tempo pessoal congela, mas o tempo pré-pessoal volta a escoar assim que somos estimulados por alguma qualidade; todo o corpo "enforma-se" para receber os estímulos. Neste momento em que o tempo pessoal e pré-pessoal se confundem,

a fusão entre a alma e o corpo no ato, a sublimação da existência biológica em existência pessoal, do mundo natural em mundo cultural, é tornada ao mesmo tempo possível e precária pela estrutura temporal de nossa experiência. (1999, p. 125)

Portanto, o ser no mundo pode ser entendido pela ambigüidade do corpo, assim como esta pode ser entendida pela do tempo. (1999, p. 126) 
Ainda com relação ao caso do membro fantasma, Merleau-Ponty mostra que não é uma causalidade psíquica que se sobrepõe à causalidade fisiológica, mas uma situação em que os estímulos no coto fazem com que o membro fantasma tenha uma atitude existencial. $^{2}$ E, segundo o filósofo francês, esta é a mesma situação das recordações e as emoções do ser no mundo. O membro fantasma é visto então como real. Portanto, esses distúrbios psicofísicos não apontam para uma união arbitrária entre corpo e alma, mas uma união que acontece a cada momento da existência. (1999, p. 131)

O corpo foge da categorização como objeto porque está permanentemente ao lado, porque temos dele uma única e invariável perspectiva. Através da visão é possível observar as partes mais distanciadas do próprio corpo, mas quanto mais o olhar se aproxima do rosto e dos olhos, menos ele se torna visto e mais se torna impensável sua ausência (refutando o solipsismo cartesiano). Mesmo que utilizemos o espelho para nos observar, o corpo ainda permanece inseparavelmente ao nosso lado. Se objetos são dados a conhecer é porque temos um corpo.

Quando pressiono minhas mãos uma contra a outra, não se trata então de duas sensações que eu sentiria em conjunto, como se percebem dois objetos justapostos, mas de uma organização ambígua em que as duas mãos podem alternar-se na função de 'tocante' e de 'tocada'. (1999, p. 137)

O que diferencia meu corpo dos objetos é que ele pode reflexionar-se para se tocar, portanto o corpo torna-se “coisa sentiente, [isto é], sujeito-objeto." (MERLEAU-PONTY, 1989, p. 195)

Como não somos capazes de nos ver (pois mesmo através de um espelho é um outro que nos olha), a única maneira de vermos nosso corpo é através do modo como a ciência o objetiva, dissecando-o, vasculhando-o, descobrindo sua estrutura e fisiologia, e que chega aos olhos do psicólogo como algo que é semelhante a ele, ao mesmo tempo que lhe é exterior. A crítica que Merleau-Ponty faz, então, de uma compreensão psicológica de corpo é que o psicólogo, supondo-se dono de uma objetividade tal como a de um químico ou de um físico, torna-se a única referência para compreender o outro:

\footnotetext{
2 "A menor subtração traz sofrimentos radicais à nossa soma indivisa. A existência dispersa nossa carne pelo espaço.” (SERRES, 2004, p. 19)
} 
[...] enquanto psicólogo falando do psiquismo, ele era tudo aquilo de que falava. Essa história do psiquismo que ele desenvolvia na atitude objetiva, ele já possuía seus resultados diante de si, ou antes, em sua existência, ele era seu resultado contraído e sua recordação latente." (1999, p. 141.)

Ele também modifica algumas noções da psicologia da espacialidade do corpo. Por exemplo, é todo o corpo que se apóia quando colocamos as duas mãos numa mesa para nos levantarmos. Não é necessário conhecermos objetivamente todos os movimento das partes do corpo (da mão colocando-se sobre a mesa, dos cotovelos se dobrando, do impulso com os quadris) para que alcancemos determinado objeto. Existe um saber que dispensa o conhecimento particularizado do movimento e da objetivação do espaço. Merleau-Ponty chama isso de "ancoragem de um corpo ativo em um objeto" (1999, p. 146). Neste momento, a espacialidade corporal torna-se uma "reserva de potência" a fim de destacar o gesto que alcança o objeto. A espacialidade do corpo e a espacialidade exterior formam um sistema que permite que o corpo e as coisas conectem-se. Esses esquemas de ancoragem são denominados fios intencionais.

O processo que faz com que cocemos determinado lugar do corpo sem que precisemos olhar para ele, ou o processo que faz com que peguemos uma tesoura sobre a mesa sem precisarmos olhar para as mãos que a alcançam não diz respeito ao corpo objetivo, mas ao corpo fenomênico. "A operação toda tem lugar na ordem do fenomenal, não passa pelo mundo objetivo [...]." (1999, p. 153) Os objetos e mesmo as partes do corpo deixam de se localizar num espaço objetivo para tornarem-se “potências já mobilizadas pela percepção”. (1999, p. 153).

Portanto, os movimentos do corpo e sua relação com o ambiente e o sistema de objetos não se dá pelo corpo objetivo, mas pelo corpo fenomênico que nele ancorase através dos fios intencionais. Por isso, para Merleau-Ponty, a consciência é transferida para o corpo, instalando-se nas coisas; pode, portanto, esquecer-se dos fenômenos, porque o esquecimento deles não é uma ausência, podendo presentificálos a qualquer momento.

O ato noético que vai em direção ao objeto não pressupõe que se conheçam todos os mecanismos fisiológicos da visão para que se apreenda o sentido daquele. Ao se captar a coisa, ela não é captada em si mesma, pois está presa ao contexto do 
corpo. O sentir está ligado ao corpo e traz à tona a espessura entre o objeto percebido e o sujeito que percebe. A coisa em si só é desvelada quando o outro também a apreende. É ao percepcionar o que o outro também percepciona que aparece um universal. É com esta noção que a comunicação se possibilita, pois as percepções conseguem identificar um mundo em comum.

Para Merleau-Ponty:

Quer se trate do corpo do outro ou de meu próprio corpo, não tenho outro meio de conhecer o corpo humano senão vivê-lo, quer dizer, retomar por minha conta o drama que o transpassa e confundir-me com ele. Portanto, sou meu corpo. (1999, p. 269)

\section{Carne, Corpo Sentiente e o Quiasma}

Em seus últimos trabalhos, Merleau-Ponty radicaliza seus conceitos, desenvolvendo uma instigante ontologia, denominada por ele de ontologia do ser bruto, que procura tanto expor na filosofia seus laços metafísicos, quanto encontrar as raízes sobre as quais se dão as relações entre os corpos, o mundo, a linguagem e o sensível.

Esta ontologia baseia-se na idéia de que antes de percebermos o outro, percebemos "uma outra 'sensibilidade' (Empfindbarkeit) e somente a partir daí um outro homem e um outro pensamento." (1989, p. 197) Este momento de contato com o outro, como aquele em que mãos se cumprimentam, é o momento de surgimento de uma intercorporeidade. É neste instante antepredicativo que acontece o encontro entre "carnes animadas" (1989, p. 197), em que surge a evidência de uma fé perceptiva que é aquém das percepções e além das subjetividades, e que constitui a base comum sobre a qual os objetos se dão em "presença originária" (Urpräsentierbarkeit ${ }^{3}$ ), isto é, "que nasce a evidência e a universalidade [das coisas] veiculadas por essas relações de essência." (Merleau-Ponty, 1989, p. 200)

Nessa ontologia do sensível, ocorre uma reflexão do corpo em si (isto é, o tocar é inerente ao tocando, ao ser tocado) em que sujeito e objeto finalmente embaralham-se; surge daí a idéia de corpo sentiente. Portanto, o sentir assume uma conotação ainda mais extrema em Merleau-Ponty que em Husserl. "O conceito

\footnotetext{
3 No glossário de termos alemães do livro O visível e o invisível (2005), Urpräsentierbarkeit é definido como presentabilidade originária.
} 
inteiro e o pensamento objetivo inteiro vivem desse fato inaugural: eu senti." (1989, p. 195-196)

Radicalizando suas investigações em torno da percepção, daquilo que é tangível e daquilo que é visível, em O visível e o invisível (2005), Merleau-Ponty acaba desenvolvendo uma instigante noção de carne que as pesquisas atuais sobre o corpo na sociedade das redes telemáticas parecem ainda não terem se dado conta. Neste trabalho, o autor afirma que aquilo que é visível possui quem vê, assim como quem vê (vidente) também possui o visível. A carne é esta espessura entre o que é visto e quem vê.

É que a espessura da carne entre o vidente e a coisa é constitutiva de sua visibilidade para ela, como de sua corporeidade para ele; não é um obstáculo entre ambos, mas o meio de se comunicarem. Pelo mesmo motivo, estou no âmago do visível e dele me afasto: é que ele é espesso e, por isso, naturalmente destinado a ser visto por um corpo. (2005, p. 132)

A carne é um conceito singular para Merleau-Ponty, afirmando que ela é fundamental para a filosofia, porque não se trata da idéia de um corpo objetivo pensado a partir de uma alma e porque rompe com a separação entre sujeito e objeto. A carne não é nem matéria, nem espírito, nem substância:

Seria preciso, para designá-la, o velho termo 'elemento', no sentido em que era empregado para falar-se da água, do ar, da terra e do fogo, isto é, no sentido de uma coisa geral, meio caminho entre o indivíduo espácio-temporal e a idéia. (2005, p. 136)

Onde quer que se encontre carne, encontra-se uma especificidade relativa a ela enquanto elemento. E essa especificidade diz respeito ao onde e quando, ao lugar e ao agora. Existe uma coesão em torno da carne e que não está necessariamente ligada à sua visibilidade, mas sim tanto à visibilidade quanto à invisibilidade e que configura o entrelaçamento entre os seres.

Pois, se há carne, isto é, se a face escondida do cubo irradia em algum lugar tão bem como a que tenho sob os olhos, e coexiste com ela, e se eu que vejo o cubo também participo do visível, sou visível de alhures; se ele e eu, juntos, estamos presos num mesmo 'elemento' [...] essa coesão, essa visibilidade de princípio prevalece sobre toda discordância momentânea." (2005, p. 136) 
A tangibilidade e a visibilidade das $\operatorname{coisas}^{4}$ que são dadas pelas mãos e olhos formam o corpo sinérgico, isto é, as pequenas subjetividades dadas pelo tocar e ver conjugam-se em torno do corpo pré-reflexivo e pré-objetivo. As percepções particulares de cada mão e olho constituem "um Sentiente em geral, diante de um Sensível em geral.” (MERLEAU-PONTY, 2005, p. 138) Portanto, se existe sinergia no interior dos corpos, deve haver também entre eles. Segundo Merleau-Ponty, isto seria possível desde que se abandonasse o pressuposto de interconexão entre o sentir e a consciência, assumindo que o sentir é a "aderência carnal do sentiente ao sentido e do sentido ao sentiente" (2005, p. 138), ou seja, a espessura entre o visível e o invisível.

Com isso, Merleau-Ponty provoca uma ruptura com o pressuposto de subjetividades encerradas no corpo, pois bastaria que compartilhássemos uma paisagem (através da fala, por exemplo), para que houvesse um entrelaçamento entre as carnes, para que fôssemos habitados por uma visibilidade comum. Há também um rompimento com a idéia de alter-ego porque assim como não há um "eu” que fala, não existe um "ele" que vê (2005, p. 138).

Existe uma espessura infindável da carne que possibilita múltiplas visões sobre ela. E é neste momento que se percebe a limitação de uma única visão sobre as coisas e, também, a percepção da visibilidade de si. "Pela primeira vez, o vidente que sou me é verdadeiramente visível; pela primeira vez, me apareço até o fundo debruçado sobre mim mesmo debaixo de meus próprios olhos.” (p. 139)

Segundo a lógica de Merleau-Ponty, o pensamento surge a partir do ver e do sentir, mas isto não quer dizer que exista um fundamento empírico nele; o pensar advém da carne que, como foi visto, é um elemento de coesão entre as coisas que não é nem matéria, nem substância, nem espírito: "consiste no enovelamento do visível sobre o corpo vidente, do tangível sobre o corpo tangente.” (p. 141) O corpo expõe sua massa quando as coisas inscrevem-se nele.

Existe um intervalo entre a voz própria e a voz articulada, entre a mão que toca e a que é tocada, mas que não é visto como um não-ser ou um vazio ontológico; é

\footnotetext{
4 Michel Serres faz uma interessante observação que parece casar com Merleau-Ponty: "A visão sofre com a mistura e sua evidência. Mais facilmente ela distingue, separa, calcula as distâncias; o olho sentiria dor com o tato." (2001, p. 63)
} 
o ponto de contato total do corpo e do mundo (2005, p. 143). Este contato é entendido por Husserl como o horizonte das coisas e que não é uma mera conceituação teórica, mas que constitui de fato um ser, "um ser de porosidade, de pregnância [...], diante do qual o horizonte se abre, aí é preso e englobado.” (2005, p. 144)

Portanto, para Merleau-Ponty, as idéias e os pensamentos vinculam-se como experiências da carne, mas que são invisíveis. É o avesso do visível, não uma sobreposição; é uma outra carne, mais leve, transparente (2005, p. 147). Este invisível, por sua vez, não é nem absoluto, nem invisível de fato, mas "invisível deste mundo, aquele que o habita, o sustenta e torna visível, sua possibilidade interior e própria, o Ser desse ente.” (p. 146) É um invisível existencial.

A carne do mundo não se confunde com nossa própria carne, mas é através daquela que compreende o corpo, assim como o corpo sensível não é o corpo sentiente. O corpo sensível é o que percepciona, enquanto o corpo sentiente é a reflexão do corpo em si, ou seja, tocar e ser tocado concomitantemente.

Portanto, segundo Merleau-Ponty, a percepção é um paradoxo, pois existe o lado que se percepciona e o lado que não se percepciona, mas que está ali.

Não vemos nem ouvimos as idéias, nem mesmo com os olhos do espírito ou com o terceiro ouvido: no entanto, ali estão, atrás dos sons ou entre eles, atrás das luzes ou entre elas, reconhecíveis na sua maneira sempre especial, única, de entrincheirar-se atrás deles [...]. (2005, p. 147)

Existe aí um "intramundo", um entreato, um quiasma, ou seja, uma abertura além do que está imediatamente dado e em que atua o sensível. E é nos reflexos, nas sombras e nos desníveis que se constitui o mundo percebido, através do qual construímos redes de significação. Relembrando Husserl, Merleau-Ponty escreve

o sensível não é feito somente de coisas. É feito também de tudo que nelas se desenha, mesmo no oco dos intervalos, tudo que nelas deixa vestígio, tudo que nelas se figura, mesmo a título de distância e como uma certa ausência. (1989, p. 200)

O corpo sensível apenas percepciona o mundo quando sua carne lhe é arrancada, inscrevendo-se nas coisas. Vidente e visível não são coincidentes, mas um invade o outro constituindo múltiplos quiasmas que não perfazem uma unidade 
sintética, e sim o sentido de Übertragung, “imbricação, irradiação do ser". (MERLEAU-PONTY, 1999, p. 235)

\section{A trajetória desviante}

O filósofo francês Michel Serres, assim como Deleuze, recuperou pensadores considerados menores dentro da história da filosofia e da ciência, adotando conceitos que foram praticamente esquecidos e refutados ao longo da história da civilização. Serres dedicou grande parte de sua obra à antropologia da ciência, como ele mesmo denominava seu trabalho, propondo novos caminhos para o conhecimento científico e que incluísse os desvios, os turbilhões e o efêmero. Propõe até mesmo uma ciência bela: "o saber não pode prescindir da beleza." (2001, p. 103) Daí sua trilha flutuante, secundária, nômade, que absorve a pluralidade do pensamento de autores variados, como Leibniz, Lucrécio, Bergson, Arquimedes. Por este mesmo motivo, a obra de Michel Serres oferece algumas dificuldades pois seu percurso filosófico não é declaradamente mencionado, e seu método utilizado dialoga constantemente com a mitologia grega e relatos pessoais para tratar dos assuntos que perpassam o texto. Desta forma, assim como num labirinto, em que precisamos seguir cuidadosamente os vestígios deixados para trás para não nos perdermos, seus trabalhos exigem um grande esforço de leitura.

A abordagem que Serres faz da questão do corpo e dos sentidos é uma antropologia histórica que dialoga constantemente com a filosofia. Ele desenvolve um estilo único, sempre remetendo ao mundo concreto. Além disso, assim como Merleau-Ponty, Serres refuta a análise reflexiva ao incluir o corpo e seus sentidos como elemento constituinte do conhecimento científico, delineando um conceito de corpo ao longo de três livros que serão aqui examinados, sendo Os cinco sentidos (2001) o primeiro deles e talvez um dos mais importantes de sua obra inteira. Publicada em 1985, na França, nesta obra, Serres festeja de fato os sentidos nas suas minuciosas descrições que abrangem desde a elaboração do vinho, até as paisagens gregas ou francesas, lembrando a exaltação do corpo vivo com que reivindica Nietzsche. Em seguida, Variações sobre o corpo (2004), publicado em 1999, também na França, é, segundo seus próprios termos, um livro que complementa o anterior, mas que se preocupa mais com o corpo e seu movimento como um todo. $\mathrm{O}$ terceiro 
livro, Hominescências (2003), apresenta um desvio em relação aos dois anteriores, pois parece mais propenso a conciliar o universo tecnocientífico aos sentidos e ao corpo. Não que o autor renegue todo seu belo trabalho anterior, mas neste livro ele procura encontrar respostas mais harmonizadas com as tecnologias digitais e do virtual.

\section{Os cinco sentidos e a quimera}

No escuro, a visão tem pouca utilidade, a não ser captar os brilhos que sobressaem de saliências. Precisamos do tato para nos guiar. Todos os outros sentidos ficam em alerta em busca de sinais de orientação. Nos momentos em que nos despojamos dos equipamentos técnicos, quando depositamos nos músculos e nos sentidos a confiança da movimentação, eles exultam. Seu amortecimento, dado por próteses e equipamentos técnicos, podem adoecê-los. (SERRES, 2001, p. 64)

Em situações limites, confiamos plenamente nos sentidos para nos salvarmos, dispensando o cogito cartesiano. "O corpo sabe dizer eu, sozinho." (SERRES, 2001, p. 13) Descrevendo o episódio em que quase naufragou, Serres aceita a tese cartesiana de que a alma se prende ao corpo em um ponto, mas refuta que este seja na glândula pineal. Neste episódio quase trágico, Serres lembra que o piloto, ao referir-se a si, incluía toda a embarcação; sua alma espalhara-se por todo o barco. Por isso, para Serres, na verdade, a alma localiza-se, num quase-ponto.

Em vários momentos, o autor remete a Merleau-Ponty, conforme vimos anteriormente. Por exemplo, ao cortar as unhas, ele percebe o deslocamento de seu corpo para a mão que segura o cabo da tesoura. Nesta situação, nota-se claramente a espessura tênue entre o que corta e o que é cortado: "De um lado, eu corto uma unha, do outro, minha unha é cortada.” (2001, p. 16) Serres também percebe que sem a reflexão do corpo em si, não existe consciência: "Sem dobra, sem contato de si sobre si mesmo, não haveria verdadeiramente sentido íntimo, nem corpo próprio, muito menos cenestesia, tampouco verdadeiramente esquema corporal [...]” (2001, p. 16) Salientaríamos a esse respeito, não apenas a consciência, mas a existência do corpo sentiente. Mas, o interessante em Serres, não é apenas o fato de lembrar, no caso, Merleau-Ponty; ao tratar da relação da reflexão do corpo em si e da consciência, ele insere uma outra questão inusitada: a flexibilidade de cada um para fazer a reflexão 
do próprio corpo. Por isso, chega a afirmar: "A ginástica inaugura e condiciona a metafísica." ${ }^{5}$ (2001, p. 17)

Para ele, a pele assume um papel preponderante porque é onde se dá a mistura entre o corpo e a alma: "na pele, a alma e o objeto se avizinham." (SERRES, 2001, p. 19) É mistura porque corpo e mundo tangenciam-se nela e através da qual estamos mergulhados no mundo:

As coisas nos banham dos pés à cabeça, a luz, a escuridão, os clamores, o silêncio, as fragrâncias, toda sorte de ondas impregnam, inundam a pele. Não estamos embarcados a dez pés de profundidade, mas mergulhados. (SERRES, 2001, p. 66)

Para o autor, a pele é historiada, constitui-se como um mapa; é história de cicatrizes, de vestígios deixados sobre ela e sobre a qual lançamos véus para esconder nossas marcas. A pele é topológica porque é tátil e, ao contrário da especialização dos outros órgãos de sentido, é órgão mais refinado e sutil. É, no entanto, suporte para aqueles que se dobram sobre ela.

Mais do que isso, os órgãos dos sentidos são singularidades, pregas e relevos que se formam sobre a pele. Recuperando o pensamento escolástico que afirmava haver sentidos externos e internos no corpo, Serres utiliza-se de um conjunto de seis tapeçarias medievais existentes no museu de Cluny que representam cada um dos sentidos para ilustrá-los. Cinco tapeçarias representam os sentidos externos - a visão, a audição, o paladar, o olfato e o tato. Nelas, o tato exerce uma função predominante: é a mão que segura a flor a ser cheirada, é a mão que segura o cabo do espelho, é a mão que acaricia o animal, é a mão que toca a tecla do órgão, é a mão que estende o dedo para a ave. O tato, percebe Serres, predomina em todas as situações. Mas e quanto à sexta tapeçaria? Que sentido interno representa? O sexto sentido esconde-se sob a pele; é o corpo próprio:

O pavilhão, sentido interno, ou corpo próprio, fecha seus véus como o corpo fecha sua pele. Véu ou invólucro abertos de portas erguidas, os órgãos dos sentidos externos. Por estas portas, vemos, ouvimos, sentimos os gostos e as fragrâncias, por estas paredes, mesmo fechadas, nós tocamos. O pano do pavilhão ou a pele do corpo podem se abrir ou fechar, o sentido externo continua salvo. $\mathrm{O}$ sentido interno veste-se de pele [...]. (2001, p. 50)

\footnotetext{
5 Não é à toa, então, que o autor dedica Variações sobre o Corpo aos seus professores de ginástica e de montanhismo.
} 
Mas Serres nota um outro detalhe existente nas tapeçarias: com exceção da última, em todas as outras as mulheres estão caladas, entregues aos sentidos particulares, distantes da linguagem. Na última, o sentido interno (representado pelo pavilhão azul, na interpretação de Serres) manifesta-se através da linguagem que ecoa através da frase: "A MON SEUL DESIR", representando um afastamento dos sentidos dado pela conquista da linguagem: a mulher abandona seus pequenos prazeres (ilustrados nas outras cinco tapeçarias) para voltar-se à escrita: "[...] o corpo chora o mundo que deixou, a mulher lamenta as jóias que abandonou, a beleza dos cinco sentidos jaz na caixa-preta enquanto dormimos sob a pintura azul gravada a fogo.” (2001, p. 52)

A frase exprime o paradoxo do corpo: brota dele para expressar-se no exterior. Para Serres, esta tapeçaria anuncia o primeiro cogito, mas não o cartesiano; lamenta a perda dos sentidos, que são colocados num cofre, e a escrita refere-se ao desejo, pois "só existo enquanto língua" (2001, p. 53). Para o autor, essa é nossa situação e por isso nada podemos escrever sobre o tato ou sobre qualquer dos outros sentidos - estamos presos na linguagem: "Não posso escrever nem dizer as cinco tapeçarias, pois, se digo ou escrevo, falo apenas da sexta. A língua original aconteceu, nada podemos fazer." (2001, p. 54) Mas ele vai mais longe ao afirmar que a palavra insensibiliza a carne, anestesia-lhe (o verbo fez-se carne) ou, pelo menos, a linguagem esvaziada.

Serres propõe então a pele como quimera, tal como um dos animais representados na tapeçaria: misto de cabra, narval e cavalo, o que chama de licorne. A pele como quimera é uma costura entre os sentidos, entre seres, entre circunstâncias. Não podemos reivindicar identidades quando somos misturas, fruto de cruzamentos, composição heteróclita. Somos e não somos ao mesmo tempo. Mais que isso: a quimera só é o que é porque realiza sua identidade no impossível, no singular. No caso do licorne, é o chifre imenso que brota no meio da fronte. Para Serres, é nessa excrescência que se realiza o sensível, a mistura. "No chifre impossível a quimera consegue, enfim, a união preparada em toda a sua pele, por alinhavos imprecisos, por justaposições bizarras.” (SERRES, 2001, p. 63)

\footnotetext{
${ }^{6}$ A frase é traduzida no livro como "unicamente meu desejo". (2001, p. 53) 
O tato desvenda a singularidade do mundo, por isso é topológico. Como escreve Serres, jamais se viu uma figura geométrica ideal, tal como uma esfera ou um cubo. Um cego, ao tatear um tijolo, percebe suas ranhuras e reentrâncias. Por que então toda a teoria do conhecimento fiou-se nelas (esfera e cubo) ao invés do tijolo e da bola? (2001, p. 80)

Segundo ele, a visão sempre exerceu papel preponderante diante dos outros sentidos porque a abstração sempre a privilegiou em detrimento do olfato, do tato e do paladar, principalmente. A visão distanciada, como num sobrevôo, enxerga panoramicamente, constrói modelos, mas desconhece a singularidade, pois tudo aparece como numa superfície, chapado. Um contato próximo do mundo, por sua vez, desfoca a visão, mas permite que se conheça seu relevo, reentrâncias e sutilezas, o que só pode ser apreendido com os outros sentidos. Conforme seus termos, "a visão oculta-se sobre o tato.” (2004, p. 14-15)

A audição tem um papel desviante em relação aos outros sentidos, pois é graças ao ouvido que nos equilibramos em relação ao mundo; ele "conhece a ubiqüidade, poder quase divino de ocupar o universal.”(2001, p. 42) Mesmo assim, ouvimos com o corpo todo porque o mundo ressoa nele: "mergulhados, afogados, engolidos, sacudidos, perdidos nas repercussões e ressonâncias infinitas que compreendemos pelo corpo.” (2001, p. 138) E por ressoar, o corpo vibra; e por vibrar, também emite.

"A estesia cura a anestesia" (2001, p. 156) escreve Serres. Os sentidos estimulados - como um bom vinho trabalha o paladar - desperta o corpo todo. Mas não basta um estímulo qualquer. É preciso degustá-los. Degustação ao invés da embriaguez. É uma outra situação que Serres explora quanto aos sentidos, porque "o olfato e o gosto diferenciam, ao passo que a linguagem, como a vista e o ouvido, integra." (2001, p. 157) Degustar é aceitar a efemeridade do estímulo, como o perfume que evapora-se no ar e como o vinho que dispersa-se na língua. Olfato e paladar são sentidos que trabalham conjuntamente, por isso, "o homem de sapiência [...] tem o nariz apurado, o ouvido fino, para captar o instante; o opiniático [...] só tem boca, ele emite, ao passo que tudo nasce da recepção sutil.” (2001, p. 157) 
Para Serres, o amor é um "raro acordo dos olfatos." (2001, p. 172) Lembrar de alguém querido está intrinsecamente ligado ao olfato, "espírito emanado de quem amamos um dia." (2001, p. 172) Assim como um buquê é a intersecção das flores que o compõe, sendo esta intersecção a sua singularidade, ao se desfazê-lo, o que se tem é a lembrança do estado das coisas. "O buquê forma a cintilação de memória pela impossibilidade de analisar o corpo misturado: apresenta-se íntegro ou não se apresenta." (2001, p. 173) Assim como o buquê, o amor não faz sentido quando não se pensa misturado.

O corpo em movimento, então, tem o papel de federar os sentidos. (2004, p. 15) Mais do que isso, é no movimento que o corpo se redescobre aquém da linguagem; "descobre sua existência no ardor muscular, quase sem fôlego, nos limites da fadiga." (2001, p. 324)

Com a abstração progressiva do mundo, sua codificação atingiu tal ponto que abrimos mão de nossos sentidos para confiar mais nas máquinas, como os marinheiros que, atualmente, "passam sem olhar os faróis, com todas as proteções garantidas na sala de escuta e nas telas de gráficos.” (2001, p. 44) É o mesmo estado da medicina atual: não se fazem mais exames físicos, baseados no toque ou na auscultação; o diagnóstico é feito diretamente sobre exames ambulatoriais, praticamente dispensando o contato entre médico e paciente.

O mundo da informação toma o lugar do mundo observado; as coisas conhecidas porque vistas dão lugar aos códigos permutados. [...] A gnosiologia muda, e a epistemologia, mas também a vida cotidiana, o nicho móvel onde o corpo mergulha [...]. (2001, p. 45)

Neste processo de ampla codificação das coisas, "a mensagem torna-se o próprio objeto." (2001, p. 45) Ao mesmo tempo, Serres reconhece aí uma identificação com o que chama de Antigüidade, quando o conhecimento se fiava nas relações e não nos objetos. Com isso, ele desloca o eixo da história da ciência ao enaltecer o transitório, o misturado e o instável:

O eu manifesta-se pouco fora das circunstâncias. Eu sou, eu existo nesta contingência misturada que muda, muda pela tempestade do outro, por sua possibilidade de existir. Nós nos colocamos um e outro em afastamento do estável, no arriscado.(2001, p. 23-24) 
No final de Os cinco sentidos, Serres elenca atividades do corpo que remetem à pura alegria: o despertar, o respirar, o saltar, o nadar, o andar, o correr, o carregar, o dançar, mas esquece-se do senso de equilíbrio, que retoma em Variações sobre o corpo. Para ele, o senso de equilíbrio foi fundamental para que o homem andasse ereto, porque o firme apoio da planta do pé permite uma boa visão: “[...] o passo constrói um ciclo cujo bom funcionamento une a visão ao toque das plantas dos pés [...]”. (2004, p. 28) Assim como Merleau-Ponty que via uma relação intrínseca entre a visão e o tato, Serres também percebe o mesmo, afirmando: "A visão caminha ou a vida cessa." (2004, p. 29) Mas o senso de equilíbrio depende também do ouvido interno e externo. É com os dois conjuntos que realizamos sempre o movimento que joga com a estabilidade e a instabilidade, alternando-se continuamente para que consigamos andar.

Como Nietzsche, que afirmava que apenas os pensamentos nascidos do movimento seriam válidos, que louvava o papel de uma boa dieta para o exercício do livre pensar, Serres escreve sobre o trabalho do escritor: "[...] exercícios físicos, dieta bastante austera, vida ao ar livre, práticas intermináveis de força e adaptação; em comparação com a escrita, um percurso na montanha vale por dez bibliotecas." (2004, p. 17) E ainda: “[...] uma vida subordinada aos ritmos do corpo, à observância rigorosa do sono e alimentação sadia.” (2004, p. 35)

Por isso, Serres valoriza, talvez como nenhum outro pensador, o treinamento e a prática física do corpo, pois seu bom funcionamento depende deles. É no treino, no exercício e na prática (não no treinamento dos superatletas, mas na prática como aperfeiçoamento do homem) que se abre espaço para o novo: "Em qualquer atividade a que nos dedicamos, o corpo é o suporte da intuição, da memória, do saber, do trabalho e, sobretudo, da invenção.” (SERRES, 2004, p. 36)

O treinamento nos livra do pensar consciente. Um pianista ou um esquiador não sabem explicar como executam suas atividades: apenas praticam e realizam. "[...] o esquiador prescinde do controle da mente e não gosta da consciência que não lhe presta nenhum serviço.” (SERRES, 2004, p. 43) Como observara Merleau-Ponty, não precisamos conhecer todos os mecanismos de um gesto para realizá-lo; ele 
simplesmente é feito. "Para habitar melhor seu corpo e também comandá-lo, esqueçam-se dele, pelo menos em parte.” (SERRES, 2004, p. 43)

\section{O corpo hominescente}

O corpo não segue as determinações da genética, pois não operamos meramente no plano de trocas metabólicas com o ambiente e nem seguimos um tempo linear. Optamos por algumas formas e abrimos mão de outras; nos metamorfoseamos. O corpo está sempre variando, está sempre adotando potências. “A liberdade se define pelo corpo e este por sua virtualidade.” (SERRES, 2004, p. 52)

Para Michel Serres, é a percepção da morte que distingue o homem dos outros animais, pois é com ela que damos sentido à vida. Por isso, quando se modifica a concepção de morte, modifica-se também a concepção de vida. Como podemos compreender então uma civilização como a nossa que cria mecanismos para driblar a morte e escamotear a dor? Uma sociedade que recusa a dor é tão desconfiável quanto a que a aceita. A consciência brota da dor, que a expande até limites máximos. "A saúde fazia de mim uma transparência muda, uma ausência, um ponto do mundo sem lugar, um não-eu; a dor o faz inflar até tomar conta de todo o meio ambiente." (2004, p. 45)

Segundo o autor, os animais precisaram da evolução para se adaptar perfeitamente ao seu ambiente, enquanto os homens conseguiram sobreviver por séculos às condições mais adversas com poucos recursos técnicos. Quando criamos um instrumento e o utilizamos, o corpo praticamente não muda ou não tem necessidade de mudar, pois driblamos a lenta transformação que opera através da mutação e seleção. Porém, ao adentrarmos nesse tempo exodarwiniano (SERRES, 2003, p. 51), perdemos uma parte de nossa corporeidade, pois transferimos funções para instrumentos e ferramentas. Por sua vez, os objetos-técnicos, que nos protegiam das mudanças, começaram a evoluir tão rapidamente que nossos corpos foram obrigados a se transformar para se adequar a eles.

Neste processo de adequação dos corpos aos objetos técnicos e mais propriamente ao mundo tecnocientífico, optamos por transferir as causas finais a nós mesmos, transformando-nos igualmente em artefatos. Portanto, para Serres, as 
ciências tomam em suas mãos o projeto humanista de construção de um outro homem transformando nossos corpos em biotecnoestruturas.

Com que finalidade interviremos no tempo de evolução e quando o faremos? Essa ação técnica, como todas as outras, contribui para apagar o acaso. Por que o eliminamos? Esta última questão se reduz a uma tautologia, porque eliminar o acaso consiste em substituí-lo por outra coisa, ou seja, uma finalidade. (SERRES, 2003, p. 60)

Por isso, ele cria o termo hominescência, uma espécie de junção entre hominização e luminescência ou incandescência, para definir este estágio da humanidade em que o homem adota o finalismo das máquinas enquanto habita espaços e tempos múltiplos. O corpo hominescente é este corpo que sofre um processo evolutivo mais brando que aquele da hominização (que resultou no andar ereto e na perda de pêlos do corpo) mas que é obrigado a se transformar para acompanhar a acelerada evolução do mundo tecnocientífico.

Criticando fortemente o fato de nosso mundo atual voltar-se muito mais para o "doce" (sendo os softwares uma das possíveis interpretações para "doce”) que para o "duro" (o mundo concreto), Serres chama a atenção para aqueles que encerram a vida no signo:

Alguns de nós sequer desconfiam, durante toda a vida, que existe um mundo fora do signo: uma ação separada do papel administrativo, um ato fora do espetáculo midiático, um clima exterior à biblioteca. (2001, p. 1999)

\section{Corpos Conjugados}

O corpo glorioso é um termo adotado tanto por Merleau-Ponty quanto Michel Serres. Em Merleau-Ponty, refere-se ao corpo iluminado pelo contato do visível e do tangível (MERLEAU-PONTY, 2005, p. 144), enquanto Serres refere-se ao corpo glorioso quando menciona o mistério da carne no cristianismo, isto é, uma carne que "participa da divindade" (2004, p. 60). Não que Serres adote uma concepção mística de corpo, mas uma que diz respeito às potências da vida que encarnam-se nesse corpo glorioso.

Além disso, carne e pele são conceitos muito próximos nos dois autores. Michel Serres não define se sua noção de pele está ligada a alguma materialidade, substancialidade ou espírito, como o faz Merleau-Ponty acerca da carne, que a vê 
como um elemento, mas a aproximação entre ambas parece bastante evidente, especialmente porque tanto carne quanto pele são as espessuras de contato entre corpo e mundo, entre o visível e o invisível, formando o quiasma, o entrecruzamento das "múltiplas entradas do mundo" (SERRES, 2001, p. 235), contato da nossa carne com a carne do mundo.

Por fim, as concepções de corpo em Merleau-Ponty e em Serres oferecem um arcabouço conceitual que pode contribuir enormente para os estudos atuais voltados para a relação entre comunicação e tecnologias digitais, pois não dizem respeito apenas ao corpo, mas à questão da imagem, da visibilidade, da carne.

\section{Referências Bibliográficas}

MERLEAU-PONTY, Maurice. Fenomenologia da percepção. São Paulo: Martins Fontes, 1999.

------ O filósofo e sua sombra. In: CHAUÍ, Marilena, sel. Textos selecionados. São Paulo: Nova Cultural, 1989.

-----. O visível e o invisível. $4^{\mathrm{a}}$. ed. São Paulo: Perspectiva, 2005.

SERRES, Michel. Hominescências: o começo de uma outra humanidade? Rio de Janeiro: Bertrand Brasil, 2003.

------. Os cinco sentidos. Rio de Janeiro: Bertrand Brasil, 2001.

------. Variações sobre o corpo. Rio de Janeiro: Bertrand Brasil, 2004. 